\title{
Dividing the Indivisible: Procedures for Allocating Cabinet Ministries to Political Parties in a Parliamentary System
}

\author{
Steven J. Brams \\ Department of Politics \\ New York University \\ New York, NY 10003 \\ United States \\ steven.brams@nyu.edu \\ Todd R. Kaplan \\ Department of Economics \\ University of Exeter \\ Exeter, EX4 4PU \\ United Kingdom \\ t.r.kaplan@,exeter.ac.uk
}

September 2002 


\begin{abstract}
Political parties in Northern Ireland recently used a divisor method of apportionment to choose, in sequence, ten cabinet ministries. If the parties have complete information about each others' preferences, we show that it may not be rational for them to act sincerely by choosing their most-preferred ministry that is available.

One consequence of acting sophisticatedly is that the resulting allocation may not be Pareto-optimal, making all the parties worse off. Another is nonmonotonictychoosing earlier may hurt rather than help a party. We introduce a mechanism that combines sequential choices with a structured form of trading that results in sincere choices for two parties. Although there are difficulties in extending this mechanism to more than two parties, other approaches are explored, such as permitting parties to making consecutive choices not prescribed by an apportionment method. But certain problems, such as eliminating envy, remain.
\end{abstract}




\title{
Dividing the Indivisible: Procedures for Allocating Cabinet Ministries to Political Parties in a Parliamentary System ${ }^{1}$
}

\author{
Steven J. Brams and Todd R. Kaplan
}

\section{Introduction}

How coalition governments in parliamentary democracies form and allocate cabinet ministries to political parties is the subject of a substantial empirical and theoretical literature. By and large, a rule of proportionality, whereby parties are given more ministries or more prestigious ministries (e.g., finance, foreign affairs, or defense) in proportion to their size, is followed. However, small centrist parties that are pivotal in coalitions (e.g., the Free Democrats in Germany) have successfully bargained for largerthan-proportional allocations (Browne and Dreijmanis, 1982; Budge and Keman, 1990; Warwick, 2001; Warwick and Druckman, 2001).

The degree to which party leaders are satisfied with their allocations will depend on their ability to use the ministries as levers of power to advance their programs or personal ambitions (Laver and Shepsle, 1994, 1996; Warwick, 2001). Their success renders coalition defections less likely and governments more durable — as measured, for example, by their tenure in office (Warwick, 1994; Grofman and van Roozendal, 1997). ${ }^{2}$

Today the governments of most parliamentary democracies tend to be either center-left or center-right. Even when there is ideological coherence, however, the task of putting together a coalition that will (i) agree on major policy decisions and (ii) meet

\footnotetext{
${ }^{1}$ We thank Paul H. Edelman, Wilfried Hinsch, Brendan O’Leary, Friedrich Pukelsheim, Peter Sozou, Avi Weiss, panelists at the 2002 APSA Annual Meeting, and seminar participants at Bar Ilan University, the London School of Economics and Political Science, the University of Exeter, and Zif-Bielefeld for valuable comments on an earlier version of this paper. Steven J. Brams gratefully acknowledges the support of the C.V. Starr Center for Applied Economics at New York University.

${ }^{2}$ The tenure of a government, however, is not the only gauge of satisfied party leaders and stable government. Italy has had almost 60 coalition governments since World War II, but some parties (e.g., the Christian Democrats) have been regular members of almost every government. Their leaders have been little affected by the rise and fall of different governments and, therefore, probably remain quite satisfied.
} 
with public favor can be a formidable task in the absence of a formal allocation mechanism.

This task is complicated when less-than-compatible parties, like the Christian Democrats and the Greens, join the same coalition. While fiscal conservatism and protecting the environment are often at odds, these parties may still be accommodated if, for instance, the Christian Democrats are given the finance ministry and the Greens the environmental-protection ministry, and each has major influence over policies in its area.

To facilitate the allocation of cabinet ministries to political parties, we propose procedures that take into account both party interests and party size. This mechanism shifts the burden of making cabinet choices from the prime minister designate, or formateur, who is usually the leader of the largest party in a coalition government, to party leaders that join the government. Thereby these procedures give party leaders primary responsibility for the make-up of the coalition government.

We assess the fairness of this procedure, based on different criteria of fairness. Our analysis is inspired by O'Leary, Grofman, and Elklit (2001), who analyzed the use of an apportionment method in Northern Ireland in 1999 to determine the sequence in which parties made ministry choices. This method works such that the largest party in a coalition gets first choice; presumably, it would choose the position of prime minister. After that, the apportionment method determines the order of choice.

For example, suppose there are three parties, ordered by size A $>\mathrm{B}>\mathrm{C}$, and there are six ministries to be allocated. If the sequence is ABACBA, A will receive three ministries, $\mathrm{B}$ two ministries, and $\mathrm{C}$ one ministry. But beyond these numbers, the sequence says that $\mathrm{A}$ is entitled to a second choice before $\mathrm{C}$ gets a first choice, and $\mathrm{C}$ gets a first choice before B gets a second choice.

If parties have complete information about each others' preferences, we show that it may not be rational for them to choose sincerely - that is, to select their most-preferred ministry from those not yet chosen. Rather, a party (e.g., A) may do better postponing a 
sincere choice and, instead, selecting a less-preferred ministry if (i) that ministry might be the next choice of a party that follows it in the sequence (e.g., B or C) and (ii) A's sincere choice is not in danger of being selected by B or C before A's turn comes up again. Such sophisticated choices, which take into account what other parties desire, can lead to very different allocations from sincere ones.

If there are only two parties, sophisticated choices and sincere choices both yield Pareto-optimal allocations: No parties, by trading ministries, can do better, based on their ordinal rankings of ministries. However, this is not true if there are three or more parties that make sophisticated choices, which was first demonstrated for sequential choices made in professional sports drafts (Brams and Straffin, 1979).

What we show here for the first time is the problem of nonmonotonicity: A political party may do worse by choosing earlier in a sequence, independent of the Pareto-optimality of the sophisticated choices. Hence, the apparent advantage that a party's size gives it by placing it early in a sequence can, paradoxically, work to its disadvantage - it may actually get more preferred choices by going later.

Like Pareto-nonoptimal allocations, nonmonotonicity cannot occur if parties are sincere. Thus, we are led to ask how sincere choices might be recovered - or induced in the first place if the parties know they "cannot get away with" insincere choices. While there is an allocation mechanism that makes sincerity optimal for two parties, there are difficulties in extending it to more than two parties.

By putting the choice of ministries in the hands of party leaders, these leaders are made responsible for their actions. Ultimately, we believe, party leaders will be more satisfied making their own choices rather than having to bargain for them. Moreover, this greater satisfaction should translate into more stable coalition governments, which is a subject that has been extensively studied by a many scholars, including Taagepera and Shugart (1989), Laver and Shepsle (1994, 1996), Blondel and Cotta (1996), van Deemen (1997), Laver and Schofield (1998), and Müller and Strøm (2000). 
The allocation procedures we analyze could go a long way toward minimizing the horse trading that typically ensues when a formateur bargains with party leaders over the ministries they will be offered. By cutting down on the rents extracted in the bargaining process, a coalition government is likely to form more expeditiously and be less costly to maintain.

This is not to say that the procedures we discuss solve all problems. Because ministries are indivisible, there will not generally be a perfect match of the claims of each party and its allocation. Furthermore, there are certain problems that are ineradicable, whatever allocation procedure is used. For example, it may not be possible to eliminate envy among equally entitled parties. Nevertheless, we believe the procedures that we discuss offer a promising start to attenuating conflicts that have plagued the formation of coalition governments and, not infrequently, led to their downfall.

\section{Apportionment Methods and Sequencing}

Most coalition governments comprise political parties holding a majority of seats in a parliament, though 15 parliamentary democracies since World War II have had one or more minority governments (Strøm, 1990). The leader of the largest party is usually offered the opportunity to put together a coalition of parties with a majority of seats. This may take days, weeks, or even months to complete (Müller and Strøm, 2000; Carmignani, 2001).

Typically, the bargaining to form a coalition begins soon after an election, which fixes the number of seats each party has in a parliament. Of course, even after a coalition has formed, there can be problems in keeping it together, as frequent government failures in Israel and Italy have demonstrated.

The number of cabinet ministries is usually a small fraction of the number of parliament members in the government coalition. Although most parliament members in 
the coalition cannot, therefore, be ministers, each party in the coalition is usually awarded at least one ministry.

Under the procedures we analyze, there is no bargaining over either the number of ministries to which each party is entitled or which ministries it will obtain. To illustrate how ministries are allocated, suppose a parliament has 400 members, so 201 members constitute a simple majority. Suppose five parties, with a total of 201 members, form a coalition government. If 15 ministries are to be allocated, there will be no problem in giving every party at least one ministry if the smallest party in the coalition has 15 members. For even though this party constitutes only $7.5 \%(15 / 201)$ of the coalition, this percentage would entitle it to 1.12 of the 15 ministries.

But now assume that smallest party has only 10 members, entitling it to $5.0 \%$ $(10 / 201)$ of the 15 ministries, or 0.75 of a ministry. Should it receive a ministry, or will a larger party be more entitled to it? This is precisely the question an apportionment method answers.

We focus on so-called divisor apportionment methods, which have been used to apportion seats in the US House of Representatives to the 50 states, based on their populations. These methods are also used to allocate seats to political parties in most parliaments, based on the votes the parties receive in an election.

Here we propose using these methods to allocate ministries (sometimes called portfolios) to political parties, based on the numbers of seats the parties have in parliament. Beyond determining the number of ministries to which a party is entitled, however, we analyze the use of divisor apportionment methods to determine the sequence in which parties choose the ministries they desire, tying this application to more theoretical research on fair division and sequential allocation procedures.

Unlike O’Leary, Grofman, and Elklit (2001), we propose emendations in the apportionment and allocation procedures used in Northern Ireland, such as allowing the parties to trade ministries after their initial selections. We also show that even if parties 
are equally entitled, there may be no allocations that satisfy certain fairness criteria, including the prevention of envy.

To begin the analysis, we illustrate the two most commonly used divisor methods that have been used to apportion parliaments (Balinski and Young, 2001). Assume that five parties, A, B, C, D, and E, hold the numbers and percentages of seats shown in the second and third rows of Table 1 .

Table 1. Webster and Jefferson Apportionments

\begin{tabular}{|l|l|l|l|l|l|l|}
\hline Party & A & B & C & D & E & Total \\
\hline Seats & 75 & 65 & 30 & 21 & 10 & 201 \\
\hline Percent & 37.3 & 32.3 & 14.9 & 10.4 & 5.0 & 100.0 \\
\hline $\begin{array}{l}\text { Quota } \\
(d=13.4)\end{array}$ & $5.60(6)$ & $4.85(5)$ & $2.24(2)$ & $1.57(2)$ & $0.75(1)$ & $15.0(16)$ \\
\hline $\begin{array}{l}\text { Webster } \\
(d=13.7)\end{array}$ & $5.43(5)$ & $4.71(5)$ & $2.17(2)$ & $1.52(2)$ & $0.72(1)$ & $(15)$ \\
\hline $\begin{array}{l}\text { Jefferson } \\
(d=10.8)\end{array}$ & $6.94(6)$ & $6.02(6)$ & $2.78(2)$ & $1.94(1)$ & $0.93(0)$ & $(15)$ \\
\hline
\end{tabular}

To determine the number of ministries to which each party is entitled, a divisor $d$ is chosen. Initially, let $d=201 / 15=13.4$, the number of government coalition members per ministry. Dividing this number into the number of seats of each party, we obtain its quota, or the exact number of ministries to which it is entitled (fourth row). For example, $\mathrm{A}$ is entitled to 5.60 ministries, whereas $\mathrm{E}$ is entitled to 0.75 of a ministry (as discussed earlier).

Because it is persons that become ministers, we cannot give fractional numbers of ministries to parties. Hence, we need to find a way to round the quotas, either up or down, to integers. 
Suppose we round the quotas up in the usual manner: Numbers with fractions greater or equal to 0.50 are rounded up, and those with smaller fractions are rounded down. Observe that these rounded quotas for the five parties, shown in parentheses in the fourth row of Table 1, sum to 16 , which is one ministry more than the number (15) to be allocated.

We can solve this excess-ministry problem by slightly increasing $d$ from 13.4 to 13.8 (all values of $d$ in the interval $[13.64,14.00]$ work), as shown in the fifth row. Thereby A's quota drops from 5.60 to 5.43, reducing its allocation from 6 to 5 seats, without changing the allocations of the other parties. Finding a $d$ such that the allocations for all parties, when rounded, sum to the total number of ministries to be allocated is an apportionment method proposed by Daniel Webster in 1832 and independently by SainteLaguë of France in 1910 (Balinski and Young, 2001). For convenience, we will refer to it as the Webster method.

Another well-known divisor method, proposed by Thomas Jefferson in 1792 and by Viktor d'Hondt of Belgium in 1878, uses a different rounding procedure. It finds a $d$ such that only the integer portions of the quotas sum to the total number of ministries. Put another way, the quotas are all rounded down, whatever their fractional remainders.

In the example in Table 1, we need to decrease $d$ quite substantially from 13.4, which gives integer portions that sum to 12 , to 10.8 (all values of $d$ in the interval [10.72, 10.83] work). When we do this, we obtain new allocations that, when rounded down, sum to 15 , as shown in parentheses in the last row of Table 1.

Notice that the Jefferson method favors the two largest parties (A and B get 6 rather than 5 ministries each), whereas the Webster method favors the two smallest parties ( $\mathrm{D}$ and $\mathrm{E}$ get, respectively, 2 and 1 ministries rather than the 1 and 0 ministries they get under the Jefferson method). In general, the Jefferson method favors large parties, which is a bias that Balinski and Young (2001) consider appropriate in apportioning seats to parties in a parliament. 
By giving parties an incentive to combine to obtain more seats, the Jefferson method encourages coalitions. Thereby it helps to thwart the fractionalization of parties common in proportional-representation (PR) systems (Rae and Taylor, 1970), especially PR systems in which the threshold for parliamentary representation is low (e.g., $0.67 \%$ in The Netherlands and 1.5\% in Israel). By contrast, Balinski and Young (2001) argue that the Webster method is better for apportioning seats to states in the House of Representatives because it is the least biased of the five divisor methods (more on these shortly), favoring neither large nor small states.

However, all five divisor methods - each of which uses a different rounding procedure - have been criticized because they violate quota (Brams and Straffin, 1982): They can give a state more than its quota rounded up or less than its quota rounded down. As a case in point, B's quota is $4.85(d=13.4)$, but the Jefferson method gives it 6 ministries. $^{3}$

Our purpose is not to argue for a particular apportionment method but, instead, to show how the two divisor methods used in the allocation of seats to parliaments - those of Webster and Jefferson-lead to a natural order in which the parties select ministries. For this purpose, let

$$
\begin{aligned}
& s_{i}=\text { seats party } i \text { receives; } \\
& a_{i}=\text { current } \text { allocation of ministries to party } i .
\end{aligned}
$$

Each apportionment method asks which party most "deserves" the next ministry to be allocated.

As one criterion of deservingness, the Webster method gives the next ministry to the party that maximizes $W_{i}=s_{i} /\left(a_{i}+1 / 2\right)$, or the number of ministries per seat if party $i$

\footnotetext{
${ }^{3}$ An apportionment method proposed in 1792 by Alexander Hamilton satisfies quota (Balinski and Young, 2001). But it is not useful for our purposes because, unlike the divisor methods, it does not yield a sequence of choices by the parties (illustrated next for the Webster and Jefferson methods).
} 
receives the next $1 / 2$ ministry. ${ }^{4}$ Clearly, if no ministries have yet been allocated, A gets to make the first choice, because $s_{i} /(1 / 2)=2 s_{i}$ is greater for A than for the four smaller parties.

But which party gets to make the next choice? Because $W_{\mathrm{B}}=65 /(1 / 2)=130$ and $W_{\mathrm{C}}=30 /(1 / 2)=60$ are greater than $W_{\mathrm{A}}=75 /(3 / 2)=50, \mathrm{~B}$ and $\mathrm{C}$ make the next two choices. But then A gets to choose a second time before D makes a first choice because $W_{\mathrm{A}}=50$ is greater than $W_{\mathrm{D}}=21 /(1 / 2)=42$. Continuing in this manner, the Webster method gives the following sequence of 15 party choices (the slash between $\mathrm{E}$ and $\mathrm{C}$ indicates a tie):

\section{Webster: ABCABDABAE/CBABD (5 A's, 5 B's, 2 C's, 2 D's, 1 E).}

The Jefferson method gives the next seat to the party that maximizes $J_{i}=s_{i} /\left(a_{i}+\right.$ 1), or the number of ministries per seat if party $i$ receives the next ministry. As with Webster, if no ministries have yet been allocated, A gets to make the first choice because $s_{i} / 1=s_{i}$ is greater for A than for the four smaller parties.

But what happens next? After A gets its first ministry, $J_{\mathrm{A}}=75 / 2=37.5$, which is less than $J_{\mathrm{B}}=s_{\mathrm{B}}=65$ but not $J_{\mathrm{C}}=s_{\mathrm{C}}=30$. Thus, B makes a first choice after A does, but then A gets to make a second choice before $\mathrm{C}$ makes a first choice. Continuing in this manner, the Jefferson method gives the following sequence of party choices (the slash between $\mathrm{C}$ and $\mathrm{A}$ indicates a tie):

\footnotetext{
${ }^{4}$ To be sure, receiving $1 / 2$ a ministry is not possible; the $1 / 2$ in the denominator of $W_{i}$ reflects the rounding of fractions equal to or greater than $1 / 2$ under the Webster method. Under the Jefferson method, as we will see, the $1 / 2$ is replaced by 1 . These constants, when added to $a_{i}$ in the denominators of $W_{i}$ (and later $J_{i}$ ), lead to stable allocations: No transfer of a ministry from one party to another reduces the inequality in representation among parties, based on different measures of inequality. The three divisor methods, in addition to those of Webster and Jefferson, that produce stable allocations are all based on different criteria of deservingness; all favor smaller parties in varying degrees (Balinski and Young, 2001; Marshall, Olkin, and Pukelsheim, 2002). Their deservingness measures (we have dropped the subscript $i$ used in $W_{i}$ and $J_{i}$ ) are $s /[a(a+1)]^{1 / 2}$ for Hill or "equal proportions," $s /[(2 a(a+1) /(2 a+1)]$ for Dean or "harmonic mean," and $s / a$ for Adams or "smallest divisors." Whereas the Webster method is used in four Scandinavian countries, and the Jefferson method in eighteen other countries, none of the other three divisor methods is used. The nondivisor Hamilton method, also called "largest remainders" (see note 2), is used in nine countries (Blais and Massicotte, 2002; Cox, 1997).
} 
Jefferson: ABABCABDABC/ABAB (6 A's, 6 B's, 2 C's, 1 D, 0 E's).

Comparing the sequences of Webster and Jefferson, notice that the two largest parties, A and B, come up earlier as well as more frequently under Jefferson, whereas the opposite is true of the two smallest parties, D and E; C appears twice under both apportionment methods. The fact that E does not appear at all under the Jefferson method does not mean that it would necessarily go unrewarded. Its reward, however, might be something other than a ministry; or ministerial portfolios might be added so that E receives one. ${ }^{5}$

\section{Sophisticated Choices}

The choice between Jefferson, which favors large parties, and Webster, which is more neutral, will depend on the degree to which one wishes (i) to encourage coalitions by giving more ministries to large parties or (ii) to render allocations more proportional to the size of parties. Besides the choice of an apportionment method, however, political parties can choose between acting sincerely or sophisticatedly.

The latter choices exploit the parties' possible knowledge of each others' preferences, which we illustrate with a simple 2-party example. Suppose there are two parties, $\{\mathrm{A}, \mathrm{B}\}$, and four ministries to be allocated, $\{1,2,3,4\}$. In addition, suppose $\mathrm{A}$ is somewhat larger than $\mathrm{B}$, so the choice sequence is ABAB. Assume the parties rank the ministries from best to worst as follows: 


$\begin{array}{ll}\text { A } & \text { B } \\ & \\ 1 & 2 \\ 2 & 3 \\ 3 & 4 \\ 4 & 1\end{array}$

\section{Example 1}

This might be the case, for example, if ministry 1 is the defense ministry, and B's interest is primarily in domestic politics.

A party makes sincere choices if, when it selects a ministry, it chooses the best one available, based on its preference ranking. Define a pair of consecutive choices by each party as a round. Then the sincere choices of $\mathrm{A}$ and $\mathrm{B}$ on the $1^{\text {st }}$ round (single underscore) and $2^{\text {nd }}$ round (double underscore) are as follows:

\begin{tabular}{|c|c|}
\hline $\mathbf{A}$ & \\
\hline $1^{\text {st }}$ round $\rightarrow \underline{1}$ & \\
\hline 2 & \\
\hline $2^{\text {nd }}$ round $\rightarrow 3$ & \\
\hline
\end{tabular}

\section{Example 1: Sincere Choices (ABAB)}

Now assume the parties have complete information - each knows not only its own ranking but also the other player's ranking. ${ }^{6}$ In this situation, choosing sincerely may not be rational and, in fact, it is not in this example.

\footnotetext{
${ }^{5}$ If one believes that small parties should be favored, a divisor method that does so, like Adams, could be used. But whatever the method used, not all sequences - including some that might be considered fair - are feasible, which is a matter we will return to later.

${ }^{6}$ Alternatively, parties might have incomplete information, which can be modeled by assuming their leaders have beliefs about the probability distributions of the preferences of other party leaders and these beliefs are known. While incomplete information might make party leaders more circumspect about trying to manipulate choices in the manner we discuss next, it is unlikely that it would eliminate the problems of Pareto-nonoptimality and nonmonotonicity that we analyze in section 4. Indeed, incomplete information
} 
To see this, note that because A knows that B does not want ministry 1, A can choose ministry 2 on the $1^{\text {st }}$ round and not fear the loss of ministry 1 . If A's and B's goals are to benefit themselves, B has no defense against A's strategy and can do no better than choose ministry 3 on the $1^{\text {st }}$ round. The resulting choices are as follows:

$\begin{array}{rr}2^{\text {nd }} \text { round } \rightarrow & \text { A } \\ 1^{\text {st }} \text { round } \rightarrow & \text { B } \\ \frac{2}{3} & \underline{3} \\ 4 & \underline{4}\end{array}$

\section{Example 1: Sophisticated Choices (ABAB)}

These choices are optimal: By making different choices on a round, neither party can ensure itself of a better allocation and could, in fact, do worse.

For the general situation of two parties' making sequential choices with complete information, there is an elegant algorithm for optimal play (Kohler and Chandrasekaran, 1971). It works "from the bottom up" as follows. B's last choice will be the ministry ranked last by A. Cross that ministry off both parties' preference lists, thereby reducing each list by one ministry.

A's last choice is the ministry that is ranked last on B's reduced list. Cross that ministry off. Continue in this fashion, with each party's next-higher choice being the ministry that is last in the reduced list of the other party, until all ministries are chosen.

To illustrate this algorithm, consider the following example ( $3^{\text {rd }}$-round choices are shown in boldface):

may aggravate these problems; moreover, the problems of envy and inequitability illustrated in section 7 do not depend on party leaders' information about each others' preferences. 


\begin{tabular}{|c|c|}
\hline $\mathbf{A}$ & \\
\hline $2^{\text {nd }}$ round $\rightarrow 1$ & \\
\hline $3^{\text {rd }}$ round $\rightarrow 2$ & \\
\hline $1^{\text {st }}$ round $\rightarrow \underline{3}$ & \\
\hline$\overline{4}$ & \\
\hline 5 & \\
\hline 6 & \\
\hline
\end{tabular}

\section{Example 2: Sophisticated Choices (ABABAB)}

Working backward from B's last choice of ministry 6 on the $3^{\text {rd }}$ round, one can show that A will select its third choice of ministry 3 on the $1^{\text {st }}$ round. In toto, A obtains its top three ministries of $\{1,2,3\}$ - or 123 for short - which is preferable to its sincere allocation of 125 , whereas B does worse than its sincere allocation of 346 by obtaining 465 .

An assignment $\boldsymbol{A}$ is Pareto-optimal if there is no different assignment $\boldsymbol{A}^{\prime}$ such that every party that receives a different allocation in $\boldsymbol{A}^{\prime}$

(i) can match a new ministry it gets in $\boldsymbol{A}^{\prime}$ to a different old ministry it gets in $\boldsymbol{A}$;

(ii) for each such match, weakly prefers the new ministry in $\boldsymbol{A}^{\prime}$; and

(iii) for at least one match, there is at least one party that strictly prefers the new ministry in $A^{\prime}$.

Note that this definition implies the two assignments compared each must have the same number of ministries. In the earlier examples, it is not hard to show that both the sincere and the sophisticated assignments are Pareto-optimal. ${ }^{7}$

\footnotetext{
${ }^{7}$ This is true in comparing individual items, but it need not be true in comparing bundles of items. For example, if parties A and B both rank four ministries in the order 1234 , and A receives 14 and B receives 23 , this assignment is not what might be called bundle Pareto-optimal if A prefers the bundle 23 and $\mathrm{B}$ prefers the bundle 14. Unequal allocations may also be bundle Pareto-optimal. In Example 1, both players will prefer the unequal assignment $(134,2)$ to the sophisticated assignment $(12,34)$ if A prefers 34 to 2 and B prefers 2 to 34 . If each party receives three or more items, bundle Pareto-nonoptimality can occur under
} 
To illustrate a Pareto-nonoptimal assignment, suppose that A's allocation is 234 and B's is 165 in Example 2. Then

- A prefers its sophisticated allocation 123, because it strictly prefers 1 to 4;

- B prefers its sophisticated allocation 465, because it strictly prefers 4 to 1 .

Hence, by trading ministries 1 and 4, the parties can both improve their allocations. Similarly, comparing the sincere assignment to A and B with the Pareto-nonoptimal assignment, both parties can improve by trading 5 and 6 .

If there are only two parties, both sincere and sophisticated choices always lead to Pareto-optimal assignments, as the preceding examples illustrate. If there are more than two parties, assignments are always Pareto-optimal if the parties are sincere (Brams and Straffin, 1979). If the parties are sophisticated, however, two problems arise.

\section{The Twin Problems of Nonmonotonicity and Pareto-Nonoptimality}

Most government coalitions include more than two parties. If there are only a handful, as is usually the case, it is likely that party leaders know well each others' rankings of ministries, especially if there are relatively few ministries to allocate.

To illustrate the problems that can arise when parties have complete information and are sophisticated, assume that there are exactly three parties, and their leaders must choose among six ministries. If the size ordering of the parties is $\mathrm{A}>\mathrm{B}>\mathrm{C}$, but they are

one of the apportionment methods. For example, assume A and B both rank six ministries in the order 12 3456 , and the sequence is $\mathrm{ABABAB}$. Then the sincere/sophisticated outcome is $(135,246)$ to $(\mathrm{A}, \mathrm{B})$. But if A prefers 24 to 15 , and B 15 to 24, this allocation is not bundle Pareto-optimal, because there is a trade (24 to A for 15 to B) that would make both parties better off even though it does not involve switching their entire allocations. Henceforth, we assume Pareto-optimality to be as defined in the text, involving item-by-item comparisons but not the comparison of bundles. Note that if an assignment is Pareto-nonoptimal, it is bundle Pareto-nonoptimal (the bundles that the parties would benefit from trading are individual items; see the subsequent text for an illustration) but not necessarily the reverse. 
close in size, the choice sequence will be $\mathrm{ABCABC}$ under both the Webster and Jefferson methods.

Suppose the three parties rank the six ministries as follows:

$\begin{array}{ccc}\text { A } & \text { B } & \text { C } \\ & & \\ 1 & 6 & 4 \\ 2 & 2 & 3 \\ 3 & 1 & 6 \\ 4 & 5 & 5 \\ 5 & 4 & 1 \\ 6 & 3 & 2\end{array}$

\section{Example 3}

Although there is no simple algorithm, like that of Kohler and Chandrasekaran (1971), for determining sophisticated choices when there are three of more parties, it is not difficult to show that the sophisticated choices in this example are in fact sincerenamely, $(\mathrm{A}, \mathrm{B}, \mathrm{C})$ receive $(12,65,43)$, as indicated in their $1^{\text {st }}$-round and $2^{\text {nd }}$-round choices below:

\begin{tabular}{|c|c|}
\hline & B \\
\hline $1^{\text {st }}$ round $\rightarrow$ & $\underline{6}$ \\
\hline & 1 \\
\hline 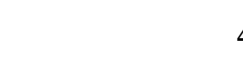 & $\underline{\underline{5}}$ \\
\hline & 4 \\
\hline & 3 \\
\hline
\end{tabular}

Example 3: Sincere and Sophisticated Choices (ABCABC)

How one shows that these choices are sophisticated is by constructing a game tree in which A can choose among its top three choices. Given these, B can choose among its 
top three choices that remain after A's choice; and C can choose among its top three choices that remain after A's and B's choices.

On the $1^{\text {st }}$ round, a party need never dip below its third choice, because the best allocation it can hope for if it does so is its first and fourth choices - 14 in the case of A. If A selected ministry 1 on the $1^{\text {st }}$ round, 14 would be the worst allocation it could obtain. Hence, choosing ministry 1 on the $1^{\text {st }}$ round weakly dominates A's choosing ministries 4, 5 , or 6 on this round: This choice is never worse, and sometimes better, than choosing ministries 4,5 , or 6 .

Thus in Example 3, this means that only $3 \times 3 \times 3=27$ branches of the game tree need be analyzed rather than $6 \times 5 \times 4=120$ branches if all available choices are considered. We will not display any game trees here but instead give intuitive explanations of why backward induction on the trees, which has all been done on the computer, produce the sophisticated outcomes we present.

To illustrate the problems of Pareto-nonoptimality and nonmonotonicity, suppose that $\mathrm{C}$ becomes the largest party and $\mathrm{A}$ the smallest in Example 4, so the previous choice sequence is reversed and becomes CBACBA. Then the parties' sincere choices are as follows:

\begin{tabular}{|c|c|c|}
\hline & C & B \\
\hline $1^{\text {st }}$ round $\rightarrow$ & & 6 \\
\hline $2^{\text {nd }}$ round $\rightarrow$ & & $\underline{2}$ \\
\hline & 6 & 1 \\
\hline & 5 & 5 \\
\hline & 1 & 4 \\
\hline & 2 & 3 \\
\hline
\end{tabular}

Example 4: Sincere Choices (CBACBA) 
Somewhat surprisingly, middle-size party B, whose two positions (second and fifth) in the sequence do not change, now gets its two best choices, whereas A, as one would expect, does worse ( $\mathrm{C}$ does the same - it cannot improve on its two best ministries under $\mathrm{ABCABC}$, even though it chooses earlier).

This time, however, the worst-off party (A) under CBACBA can escape from its poor allocation by choosing insincerely on the $1^{\text {st }}$ round: By selecting ministry 3 rather than ministry 1 initially (choosing ministry 2 does not help), A gets 13 when the other two parties are sincere. But the resulting allocation for $\mathrm{C}, 45$, is poor; it can respond optimally by choosing ministry 6 on the $1^{\text {st }}$ round (choosing ministry 3 does not help), in which case it gets 46 when the other players respond optimally by choosing sincerely thereafter. The upshot is the following sophisticated choices:

\begin{tabular}{|c|c|}
\hline $\mathbf{C}$ & B \\
\hline $2^{\text {nd }}$ round $\rightarrow \underline{4}$ & 6 \\
\hline 3 & $\underline{2}$ \\
\hline $1^{\mathrm{st}}$ round $\rightarrow \underline{6}$ & 1 \\
\hline 5 & $\underline{5}$ \\
\hline 1 & 4 \\
\hline 2 & 3 \\
\hline
\end{tabular}

\section{Example 4: Sophisticated Choices (CBACBA)}

The switch from choice sequence ABCABC (Example 3) to CBACBA (Example 4), when the largest party (A) becomes the smallest and the smallest party (C) becomes the largest, leads to two anomalies when players are sophisticated: ${ }^{8}$

\footnotetext{
${ }^{8}$ Neither of these problems can occur if there are only two parties, however many choices they have. Nonmonotonicity is precluded by the Kohler and Chandresekaran (1971) algorithm, because it gives priority to a party that makes an earlier selection; Pareto-optimality is shown by Brams and Straffin (1979).
} 
(i) Nonmonotonicity: C does worse going earlier-when it moves up from positions 3 and 6 in sequence $\mathrm{ABCABC}$ to positions 1 and 4 in sequence CBACBA (a total of 4 position changes forward);

(ii) Pareto-nonoptimality: All players—not just C—do worse when the choice sequence changes.

Brams and Straffin (1979), using a different example, showed that underlying (ii) is an $n$-person Prisoners' Dilemma, whereby all players are worse off when they make sophisticated choices in a different sequence. ${ }^{9}$ To be sure, if a change in a choice sequence hurts all players, as is true when we go from sophisticated choices in Example 3 to sophisticated choices in Example 4, it necessarily creates a monontonicity problem for the party or parties whose positions move up in the sequence but do worse as a result of the change.

But there may also be a nonmonotonicity problem when the sequence change leads to another Pareto-optimal assignment, as illustrated by the following example in which the choice sequence is $\mathrm{ABCABC}$ :

\begin{tabular}{|c|c|}
\hline$A$ & B \\
\hline $2^{\text {nd }}$ round $\rightarrow 1$ & $\underline{6}$ \\
\hline 2 & 5 \\
\hline $1^{\text {st }}$ round $\rightarrow 3$ & 3 \\
\hline 4 & $\underline{4}$ \\
\hline 5 & 2 \\
\hline 6 & 1 \\
\hline
\end{tabular}

\section{Example 5: Sophisticated Choices (ABCABC)}

\footnotetext{
${ }^{9}$ They also showed that the sophisticated outcome, compared with the sincere outcome, can make all players worse off without a change in the sequence, which is not true in either Example 3 or Example 4.
} 
Like C in Example 4, A begins by choosing its third-best ministry (3). This time, however, the third player to choose (C) is also not sincere, selecting ministry 5 on the $1^{\text {st }}$ round in order to obtain its best ministry (2) on the $2^{\text {nd }}$ round.

Now when the sequence changes to ABCCBA, the new sophisticated outcome is also Pareto-optimal (notice that because the $2^{\text {nd }}$-round sequence is CBA, C immediately gets a $2^{\text {nd }}$-round choice after its $1^{\text {st }}$-round choice) $:^{10}$

$$
\begin{aligned}
& \text { A B C } \\
& 1^{\text {st }} \text { round } \rightarrow \begin{array}{ccl}
\underline{1} & \underline{6} & 2 \\
\underline{2} & 5 & \underline{3} \\
3 & 3 & \underline{\underline{5}} \leftarrow 2^{\text {nd }} \text { round } \\
4 & \underline{4} & 6 \\
5 & 2 & 1 \\
6 & 1 & 4
\end{array}
\end{aligned}
$$

\section{Example 6: Sophisticated Choices (ABCCBA)}

The switch to ABCCBA causes A to select its second best-ministry (2) on the $1^{\text {st }}$ round, but the parties are sincere thereafter.

Observe that when C's second choice in sequence $\mathrm{ABCABC}$ moves up two positions from sequence $\mathrm{ABCCBA}$, its allocation worsens from 25 to 35; also, when A's second choice moves down two positions after the change, its allocation improves from 13 to 12 (C's allocation, 64 , is the same in both assignments). Because position changes both up and down in the choice sequence lead to nonmonotonicity, we call this two-sided nonmonotonicity. It cannot occur if the new assignment is Pareto-nonoptimal, as in Example 4, because no party can benefit after the change.

\footnotetext{
${ }^{10}$ We note here that no apportionment method can give choice sequence ABCCBA, which is an issue we discuss in section 5 .
} 


\section{Possible Solutions: Trading and Different Sequencing}

One solution to the Pareto-nonoptimality problem would be to allow the parties to trade ministries after they make sophisticated choices. However, no simple two-party trades can save all parties from the Pareto-nonoptimal outcome in Example 4. It takes a three-way trade in which A gives ministry 3 to $\mathrm{C}, \mathrm{C}$ gives ministry 6 to $\mathrm{B}$, and $\mathrm{B}$ gives ministry 2 to A to restore the sincere/sophisticated Pareto-optimal choices of ABCABC (Example 3), wherein $\mathrm{A}$ and $\mathrm{C}$ get their two best ministries and $\mathrm{B}$ gets its best and fourthbest ministries.

The nonmonotonicity of Example 4 is actually more extreme than we indicated. Compare the choice sequence $\mathrm{AABBCC}$ with $\mathrm{CACBAB}$, wherein $\mathrm{C}$ moves up a total of 7 positions. It turns out that the first sequence gives the same sincere/sophisticated outcome as does $\mathrm{ABCABC}$ in Example 3, and the second sequence the same sophisticated outcome as CBACBA in Example 4. The fact that $\mathrm{C}$ does worse when it chooses first and third than when it chooses fifth and sixth—and gets its two best ministries in the latter case! - is startling, suggesting that there are circumstances when "the last shall come first."11

In fact, however, such an extreme case of nonmonotonicity cannot occur under the apportionment methods. Thus in the case of CACBAB, there are no party sizes that can lead to this sequence under either the Jefferson or the Webster methods. Although the sub-sequence $\mathrm{CACBA}$ — comprising the first five positions in sequence $\mathrm{CACBAB}$ - are feasible if $\mathrm{C}$ is the largest party, A next-largest, and B smallest, B cannot be in the sixth

\footnotetext{
${ }^{11}$ The switch from $\mathrm{AABBCC}$ to $\mathrm{CACBAB}$ is the most extreme example in which nonmonotonicity for $\mathrm{C}$ can occur. If the latter choice sequence were $\mathrm{CCAABB}, \mathrm{C}$ can guarantee its two best ministries, precluding nonmonotonicity. If we want to keep the ordering of $\mathrm{A}$ and $\mathrm{B}$ the same as in $\mathrm{AABBCC}$, the most extreme
} 
position; C must come next. ${ }^{12}$ Similarly, choice sequence AABBCC also cannot occur under the Jefferson or Webster methods.

The infeasibility of certain choice sequences because apportionment methods preclude them raises a serious question about their use in parties' choosing cabinet positions sequentially, even when there is no monotonicity problem. Take the sequence ABCCBA, which we used to illustrate two-sided nonmonotonicity in Example 6. This sequence is not feasible under any apportionment method because the smallest party, $\mathrm{C}$, implied by the initial sub-sequence, $\mathrm{ABC}$, can never get a second choice before the two larger parties, A and B, get their own second choices.

But ABCCBA might be the fairest sequence if the three parties are roughly equal in size: It compensates for the boost given to parties A and B, at the start, by giving party C two consecutive choices later, which Brams and Taylor (1999, ch. 3) call balanced alternation. Yet all the apportionment methods rule out this sequence, however close in size $\mathrm{A}, \mathrm{B}$, and $\mathrm{C}$ are, as long as they are not equal.

One could, of course, simply mandate the use of balanced alternation in a situation like this. Such a mandate would acknowledge that because A and B benefit from choosing first and second - especially when all parties agree on which ministries are most important $-\mathrm{C}$ needs to be compensated with two consecutive choices thereafter.

Unfortunately, this acknowledgment may ring hollow if the parties are sophisticated. ${ }^{13}$ Because the balanced sequence ABCCBA gives the same Pareto-

switch illustrating monmonotonicity is the switch to CAACBB, whereby $\mathrm{C}$ moves up 6 positions rather than 7.

${ }^{12}$ Under the Jefferson method, the third and fourth positions of $\mathrm{C}$ and $\mathrm{B}$ imply that $\mathrm{C}$ more deserves to receive a second ministry than $\mathrm{B}$ deserves to receive a first ministry, so $s_{\mathrm{C}} / 2>s_{B}$ or $\mathrm{s}_{\mathrm{C}}>2 s_{\mathrm{B}}$. But for B to be in the sixth position, its deservingness in receiving its second ministry must be greater than C's deservingness in receiving its third ministry, so $s_{\mathrm{B}} / 2>s_{\mathrm{C}} / 3$, or $s_{\mathrm{C}}<(3 / 2) s_{\mathrm{B}}$, which is a contradiction. 
nonoptimal outcome as does CBACBA (and CACBAB) in Example 4, a three-way trade is needed to restore Pareto-optimality. Wouldn't it be better for the parties to use the original sequence, $\mathrm{ABCABC}$, and not have to "trade up" to Pareto-optimality afterwards?

\section{A Two-Party Mechanism}

So far we have shown that if Pareto-optimality is lost when sophisticated parties select ministries in some order prescribed by an apportionment method, it can be restored. However, trades that do so may not be easy to arrange, especially if they require a coordinated exchange of ministries among more than two parties.

While this is a practical difficulty, there is a more fundamental theoretical problem with the apportionment methods themselves. If one party is slightly larger than another, every apportionment method prescribes that the larger party choose before the smaller party on every round. This advantage can grow and grow and would, therefore, seem unfair to the (slightly) smaller party. But because of nonmonotonicity, giving the smaller party earlier choices may actually hurt it —as well as other parties if the sophisticated outcome is Pareto-nonoptimal.

Is there a way around these problems? If the players are sincere, these problems disappear. But it is naïve to suppose that political party leaders do not know a good deal about their competitors' preferences for ministries. Almost surely they do; why would they not exploit this information in making their own optimal choices?

\footnotetext{
${ }^{13}$ If the parties are sincere so choices are monotonic, even balanced alternation will not necessarily produce the most balanced outcome. To illustrate, assume A's ranking is 1234 and B's is 2341 . Choice sequence $\mathrm{ABAB}$ gives $(13,24)$ to $(\mathrm{A}, \mathrm{B})$, whereas choice sequence ABBA gives $(12,34)$, which is obviously one-sided in favor of B. In this instance, B's earlier second choice throws off the "balance." A notion of balance is formalized in Herreiner and Puppe (2002), who discuss procedures for finding it.
} 
There is one situation, however, in which party leaders can be induced to be sincere. If they are not, the sincere outcome can still be implemented, as a subgameperfect equilibrium, through swaps of ministries.

The mechanism we present next works for two parties, making it optimal for each to choose its most-preferred ministry on every round-lest it have to swap ministries later to reach precisely this (sincere) outcome. Here are the rules that render sincere choices a subgame-perfect equilibrium when two parties take turns selecting ministries. ${ }^{14}$

1. At the time of selection, a party may offer to swap a ministry that it selects for one previously chosen by the other party.

2. This offer is placed on the table until all ministries are selected.

3. After all ministries are selected, start with the most recent swap offer and go back to all previous offers. If the party offered a swap agrees to it, a swap is made. ${ }^{15}$

To illustrate this mechanism, consider again Example 1 and the sophisticated choices the parties make that result in assignment $(12,34)$ to $(\mathrm{A}, \mathrm{B})$ when the choice sequence is $\mathrm{ABAB}$ :

A B

\footnotetext{
14 "Taking turns" need not be strict alternation- $\mathrm{ABAB}$ to allocate four ministries - that all apportionment methods prescribe if $\mathrm{A}$ is less than twice as large as $\mathrm{B}$; $\mathrm{AABA}$ and $\mathrm{AAAB}$ are also feasible as $\mathrm{A}$ becomes larger and larger compared to $\mathrm{B}$. Whereas the balanced-alternation sequence, $\mathrm{ABBA}$, is never feasible under an apportionment method, we do not rule it out as a choice sequence, especially if two parties are close in size. Thus in Example 1, the sophisticated outcome under ABBA is $(12,34)$ to $(\mathrm{A}, \mathrm{B})$, in which A selects ministry 2 on the $1^{\text {st }}$ round and B follows by selecting ministries 3 and 4 . Applying our two-party mechanism if A insincerely chooses ministry 2 on the $1^{\text {st }}$ round, B would next select ministries 1 and 3 and offer to swap ministry 1 for A's ministry 2 . This swap would be rational and restore the sincere assignment of $(13,24)$ to $(A, B)$ under the rules described in the text.

${ }^{15}$ The purpose of rule 3 is to ensure that there is not a multiplicity of offers on the table, all "up for grabs." By imposing an ordering for swapping, the rule precludes bargaining over whose offer takes precedence. Instead, it induces parties to respond to "skipping" as soon as they are hurt by it (see text).
} 


$$
\begin{array}{rr}
2^{\text {nd }} \text { round } \rightarrow & \frac{1}{\underline{1}} \\
1^{\text {st }} \text { round } \rightarrow & \frac{2}{3} \\
4 & \underline{\underline{4}} \\
4 & 1
\end{array}
$$

\section{Example 1: Sophisticated Choices (ABAB)}

If the players have complete information about each other's preferences, then B would know that $\mathrm{A}$ is insincere when it selects ministry 2 on the $1^{\text {st }}$ round. When this happens, suppose that B selects, on its next turn, A's most-preferred ministry 1 (i.e., the one A skipped over) and offers to swap it for ministry 2 , which B prefers.

At the conclusion of the $1^{\text {st }}$ round, ministries 3 and 4 are still available. On the $2^{\text {nd }}$ round, if A and B sincerely choose ministries 3 and 4, respectively, it will not be in B's interest to offer A a swap of ministry 4 for ministry 3. Hence, this offer will not be made; moreover, even if it were, it would not be accepted by A.

But assignment $(23,41)$ to $(\mathrm{A}, \mathrm{B})$ is Pareto-nonoptimal. Clearly, it would be in A's interest to accept B's offer to swap ministries 1 and 2, yielding the Pareto-optimal assignment of $(13,24)$, which is the sincere outcome. ${ }^{16}$ This outcome gives each party its first and third choices, compared with the sophisticated outcome in which A gets its two best ministries and $\mathrm{B}$ its two middling ministries.

Similarly, in Example 2, the sincere assignment of $(125,346)$ to $(\mathrm{A}, \mathrm{B})$ is more "balanced" than the sophisticated assignment, $(123,465)$, which gives A its top three ministries and B its second, fourth, and fifth-best ministries. The former can be induced by if B chooses ministry 2 (its last choice) —skipping over all its preferred ministries-

\footnotetext{
${ }^{16}$ Clearly, A would prefer a swap of ministries 1 and 3 to restore Pareto-optimality, yielding $(12,34)$ rather than $(13,24)$ as the Pareto-optimal outcome. But rule 3 rules out this swap, illustrating why ex-post trading
} 
after $\mathrm{A}$ insincerely chooses ministry 3 on the $1^{\text {st }}$ round. If B offers to swap ministry 2 for ministry 3, and A accepts, both parties improve the Pareto-nonoptimal assignment of $(134,652)$ to the Pareto-optimal sincere assignment of $(124,365)$.

Notice in this example that B, as an inducement to A, will choose and then offer to swap ministry 2 - rather than ministry 1 , the other ministry A skips over-when A selects ministry 3 on the $1^{\text {st }}$ round. If B had chosen and offered to swap ministry 1 for ministry 3, A would have accepted but B would have "shot itself in the foot," because it also prefers ministry 3 to ministry 1 .

We now show that if the sophisticated outcome differs from the sincere outcome, it will be in the interest of at least one player (say, B) to offer to swap a ministry with the other player (A). In turn, it will be in the interest of A to accept this offer. The resulting outcome will be the sincere outcome, restored.

More precisely, B will offer to swap a ministry with A when (i) A is not sincere, and (ii) at least one of the ministries A skips over is a ministry that B ranks lower than the ministry that A chose. Thus, $\mathrm{A}$ and $\mathrm{B}$ have opposite preferences for a ministry that $\mathrm{A}$ chose and a ministry that A skipped over. Then B will choose a skipped-over ministry on which the players have opposite preferences and offer a swap to A, which it will be rational for A to accept. After all such offers are made and accepted by both parties, the sincere outcome will be restored. We offer a formal proof of this result in the Appendix.

Although one might think that this argument could be extended to more than two parties, the following example, in which the sophisticated choices are indicated for choice sequence $\mathrm{ABCABC}$, shows why this is not the case:

may not restore the sincere outcome, especially if one player, like A in this example, can dictate the trade that will be made because it has greater bargaining power. 


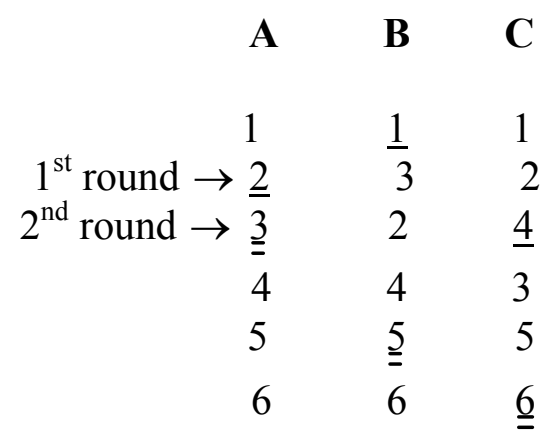

\section{Example 7: Sophisticated Choices (ABCABC)}

These choices presume that A prefers the pair 23 to the pair 14, which it can achieve by selecting ministry 1 on the $1^{\text {st }}$ round and ministry 4 on the $2^{\text {nd }}$ round. Instead, by selecting ministry 2 initially, which is an insincere choice, the sophisticated assignment becomes $(23,15,46)$ to $(\mathrm{A}, \mathrm{B}, \mathrm{C})$.

What can C do to restore the sincere outcome, $(14,35,26)$, which it prefers to the sophisticated outcome? ${ }^{17}$ After A selects ministry 2 and B selects ministry 1 on the $1^{\text {st }}$ round, C can no longer select ministry 1 that A skipped over and offer to swap it for A's ministry 2. Although $\mathrm{C}$ could select ministry 3 that both $\mathrm{A}$ and $\mathrm{B}$ would like as $2^{\text {nd }}$-round choices, either A or B could respond by selecting ministry 4 and offering to swap it for ministry 3 , which $\mathrm{C}$ prefers. Hence, $\mathrm{C}$ can do no better than sincerely select ministry 4 on the $1^{\text {st }}$ round, whence all the players will make sincere choices on the $2^{\text {nd }}$ round (in general, players can do no better than be sincere on a last round).

To summarize, we have shown that there is a two-party mechanism that can induce the parties to be sincere. But if one party is not, the other party can respond by offering a swap that, when accepted, restores the sincere outcome. Thereby sincerity is rendered optimal, whether the parties are sincere initially or swaps are used to restore the sincere

\footnotetext{
${ }^{17}$ Because B prefers the sophisticated outcome, it would have no incentive to help $\mathrm{C}$ in this restoration.
} 
outcome, which is a subgame-perfect equilibrium in a game of complete information. This mechanism, however, does not generalize to an $n$-person mechanism that restores sincerity.

\section{Equitability, Envy-Freeness, and Pareto-Optimality}

The party that benefits from a sophisticated outcome may not be the first-choosing party (A), as was true in all our previous two-party examples. In the example below, B obtains its top two ministries, and A its first and third choices, when the choice sequence is $\mathrm{ABAB}$ and the parties are sophisticated (notice that it is $\mathrm{B}$, not $\mathrm{A}$, that skips over its first choice, ministry 4 , on the $1^{\text {st }}$ round):

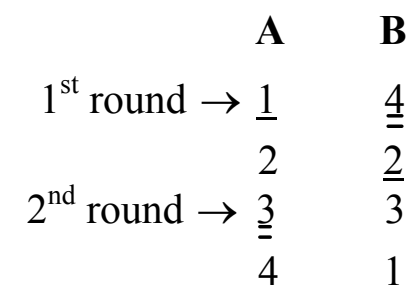

\section{Example 8: Sophisticated Choices (ABAB)}

In this example, the two-party mechanism enables A to restore the sincere outcome, turning the tables on B by ensuring its two top choices and B's first and third choices. A does so by selecting ministry 4 on the $2^{\text {nd }}$ round, after B insincerely selects ministry 2 on the $1^{\text {st }}$ round, and offering to swap it for ministry 2 . It is rational for B to accept A's offer, which turns the Pareto-nonoptimal assignment of $(14,23)$ into the Pareto-optimal sincere assignment of $(12,43)$ to $(\mathrm{A}, \mathrm{B})$. 
In this example, the sincere and sophisticated assignments are the only two Paretooptimal assignments that give two ministries to each party. ${ }^{18}$ Because the sincere assignment favors A and the sophisticated assignment favors B, there is no Paretooptimal assignment that benefits both parties "equally."

Call an assignment equitable if two or more parties (i) receive an equal number of ministries and (ii) rank them exactly the same (Brams and Taylor, 1996, 1999). In Example 1, the sincere assignment of $(13,24)$ to $(A, B)$ is equitable.

If there is not an equitable assignment, typically one party will do better than the other, as measured by their comparative rankings. ${ }^{19}$ Perhaps it is appropriate in Example 8 that the sincere outcome — or its restoration via the two-party mechanism—benefits A when the choice sequence is $\mathrm{ABAB}$. However, if the choice sequence is the balancedalternation sequence ABBA, the sincere outcome is $(13,42)$, favoring B. Moreover, there is nothing that A can do to turn the tables on B in this example, because the sincere and sophisticated outcomes coincide.

What other properties, besides equitability, are impossible to guarantee? One might hope that one party's envy of another can be prevented. In fact, this is true in Example 8: Whichever of the two Pareto-optimal assignments that give A and B two ministries each is implemented, neither party will envy the other.

For instance, if the assignment is $(12,43)$ to $(\mathrm{A}, \mathrm{B})$, which favors $\mathrm{A}$ in terms of comparative rankings, B will not desire the ministries that A receives. Because B prefers

\footnotetext{
${ }^{18}$ Brams and King (2002) prove that an assignment is Pareto-optimal if and only if it is the product of sincere choices in some sequence. Of the six different sequences that give two ministries to each party, four (ABAB, ABBA, AABB, BAAB) lead to the sincere $(12,43)$ outcome that benefits $\mathrm{A}$, and two (BABA, BBAA) lead to the sophisticated $(13,42)$ outcome that benefits B.

${ }^{19}$ In Example 8, giving 14 to one party and 23 to the other might also be considered fair, but this assignment is Pareto-inferior to both $(12,43)$ and $(13,42)$ to $(\mathrm{A}, \mathrm{B})$.
} 
ministry 4 to ministry 2 and ministry 3 to ministry 1 , it will prefer the package 43 to the package 12 , assuming there are no complementarities - that is, the value of a package is the sum of the values of its constituent parts. ${ }^{20}$

In making envy comparisons, we assume two or more parties are awarded the same number $m$ of ministries. An assignment is envy-free if and only if no party envies another party for getting a preferred $m$-allocation. Trivially, if there are only two parties that rank two ministries the same, the party that gets the preferred ministry will envy the party that gets the nonpreferred ministry.

One might think that if the parties are given more than one ministry each, it would be possible to find an assignment that is envy-free. As a case in point, consider the following example in which two parties rank four ministries and each receives a 2allocation:
A: 1234
B: 1342

\section{Example 9}

There are three Pareto-optimal 2-allocations to (A, B): $(12,34),(23,14)$, and $(24,13)$.

In the case of the last, A assuredly envies B because A prefers B's ministry 1 to its ministry 2 and B's ministry 3 to its ministry 4, so this allocation is envy-ensuring (Brams, Edelman, and Fishburn, 2002; see also Brams and Fishburn, 2000; Edelman and Fishburn, 2001; Brams, Edelman, and Fishburn, 2001).

\footnotetext{
${ }^{20}$ More formally, the utilities that parties receive for ministries are additive. The preferences underlying these utilities are said to be separable when they do not depend on which ministries a party has already acquired as the allocation process proceeds. As we show next, separable preferences still allow for envy, because envy depends on what ministries other parties receive, compared with one's own allocation.
} 
In the case of the first two 2-allocations, envy is not assured, but it is possible. For instance, consider the 2-allocation $(12,34)$. Although A definitely does not envy B, B may envy A for getting B's best and worst ministries compared with the two middleranked ministries it obtains, so this allocation is envy-possible. In general, if there are two or more parties that each receives one or more ministries, there may be no envy-free allocation-one that is neither envy-ensuring nor envy-possible.

If one insists that a Pareto-optimal allocation also be maximin - maximize the minimum rank of a ministry that any party receives - every such assignment may ensure envy (Brams and King, 2002; see also Herreiner and Puppe, 2002), as illustrated by the following example:
A: 123456
B: 123456
C: 154623

\section{Example 10}

There are six Pareto-optimal maximin assignments to (A, B, C), in which each party obtains no worse than a fourth-best ministry: $(14,23,56),(23,14,56),(13,24,56),(24$, $13,56),(12,34,56),(34,12,56)$. But one party assuredly envies another in all these assignments. Take, for example, assignment $(14,23,56)$. C prefers the two items that A receives to the two items that it receives.

Curiously, to avoid envy, parties may have to settle for a Pareto-nonoptimal assignment, as illustrated in our final example (Brams, Edelman, and Fishburn, 2001): 

A: 123456
B: 432156
C: 512634

\section{Example 11}

The unique envy-free assignment is $(13,42,56)$ to $(\mathrm{A}, \mathrm{B}, \mathrm{C})$. Clearly, A prefers its two items to those of B (which are A's second-best and fourth-best items) and to those of C (A's two worst items). Likewise, B and C prefer their items to those of the other two parties. Consequently, all three parties prefer their items to those of the other two parties, so the allocation is envy-free.

Compare this assignment with $(12,43,56)$, whereby $\mathrm{A}$ and $\mathrm{B}$ receive their two best items, and $\mathrm{C}$ receives, as before, its best and fourth-best items. This allocation weakly Pareto-dominates envy-free assignment $(13,42,56)$, because two of the three players (A and B) prefer their items in $(12,43,56)$, whereas both allocations give player C the same two items $(56)$. Thus, while $(12,43,56)$ is Pareto-optimal, C may envy A. Hence, this example requires one to choose between (i) a Pareto-optimal, envy-possible assignment and a (ii) a Pareto-nonoptimal, envy-free assignment. Is one unequivocally better than the other?

In this section we have shown that whatever procedure is used for allocating ministries, there may be no Pareto-optimal assignment that is either equitable or envyfree. On the other hand, if there is an envy-free assignment, as in Example 11, it may not be Pareto-optimal, which is also true of equitable assignments - the only one may be Pareto-nonoptimal (Brams and King, 2002). Clearly, the desiderata of fair division are sometimes incompatible, necessitating some hard choices in dividing the indivisible. 


\section{Conclusions}

The fact that both equitable and envy-free allocations may be unachievable, or achievable only if an allocation is Pareto-nonoptimal, would seem to deal a fatal blow to the fair division of indivisible items like cabinet ministries. But our interest is not in fairness as such, except in the special case that two or more parties are almost the same size (more on this below). Rather, it is in finding allocations that reflect the entitlements of parties, based on their size and perhaps other prerogatives. ${ }^{21}$

For this purpose, the divisor methods of apportionment offer promise, because they provide a way to allocate ministries sequentially, with the most deserving parties given priority. Different apportionment methods define deservingness differently, but all relate it to size. Thus, the Jefferson method tends to favor large parties, whereas the Webster method is more neutral.

But more than offering promise, the Jefferson method was used in November 1999 to allocate ten cabinet ministries to the "grand coalition" of four major parties represented on the Northern Ireland Executive Committee, the main governing body of Northern Ireland today. This method has been also been used for more than half a century to allocate positions on local government councils in major Danish cities (O’Leary, Grofman, and Elklit, 2001).

In Northern Ireland, it is not evident whether, if trades of ministries had been permitted (they were not), any trades would have been made or if this would have affected the final allocation. But there is little doubt that the parties were quite well

\footnotetext{
${ }^{21}$ In Northern Ireland, where single transferable vote (STV) is used in elections, the party that receives the most first-place votes under STV receives priority in the event of a tie as to which party is awarded the next ministry (O'Leary, Grofman, and Elklit, 2001). For information on voting processes in other countries, see Colomer (2001).
} 
informed about each others' top preferences. Furthermore, there may have been some strategizing, as evidenced by a number of surprising (insincere?) choices of ministries by the parties at different times in the allocation process (O'Leary, Grofman, and Elklit, $2001) .^{22}$

Because the sophisticated choices of parties may lead to a Pareto-nonoptimal outcome, we think trades of ministries should be permitted. In professional sports drafts in the United States, trading is not only commonplace after the draft but sometimes involves future draft choices — even before the players that will be in the draft are known-as well as money. ${ }^{23}$

That early choices are not necessarily beneficial, nor late choices harmful, shows how sophistication can nullify, or even reverse, the favorableness of one's position in a choice sequence. We strongly doubt, however, that political parties would actually give up early choices for later ones because they foresee a monotonicity problem.

More serious, we think, is the problem caused by parties that differ only slightly in size. If there are only two large parties, as was the case in Northern Ireland (together they received $60 \%$ of the ministries), being fair to both parties translated into giving each party one first minister and one junior minister (“dual premiers"). Indeed, these four positions were above and beyond the six (of ten) specialized ministries the two largest parties were awarded by the Jefferson method; altogether, they ended up with 10 of the 14 ministries, or 71\% (O’Leary, Grofman, and Elklit, 2001).

\footnotetext{
${ }^{22}$ This surprise, however, might simply have reflected inaccurate information that the parties had about each others' lower preferences.

${ }^{23}$ It is, therefore, not strictly indivisible goods that are being divided, which usually facilitates the division process but does not necessarily eliminate envy (Young, 1994, 1995; Brams and Taylor, 1996, 1999; Robertson and Webb, 1998; Brams and Kilgour, 2001).
} 
In most parliamentary systems, being the prime minister is far more important than being any other minister (Laver and Hunt, 1992; Warwick, 2001; Warwick and Druckman, 2001). If there are two large parties, therefore, it would seem sensible to use balanced alternation, or ABBA in selecting the first four ministries (BAAB would follow as the next sequence of choices under balanced alternation). For example, if A received the prime ministership, and foreign affairs and finance were considered the most prestigious specialized ministries, B would get both of these before A would get a second choice under ABBA.

In the case of two parties, we gave a mechanism that ensured that sincere choices are optimal—either initially or after rational swaps are made—given the parties have complete information and can propose such swaps. This mechanism is needed even in the case of the balanced-alternation sequence $\mathrm{ABBA}$, wherein $\mathrm{B}$ can do no better than be sincere in its two consecutive selections (see note 15). We leave open how close in size two or more parties must be to justify use of a balanced-alternation sequence, like ABBA for two parties or ABCCBA for three parties.

No mechanism or sequential procedure can guarantee either equitable or envy-free allocations. Indeed, those that satisfy these fairness criteria, even if they exist, may be Pareto-nonoptimal, requiring trades to improve everybody's allocation. ${ }^{24}$

Speaking pragmatically, we believe the use of divisor apportionment methods can abet cabinet selection by putting responsibility in the hands of party leaders. By fixing the number and order of party choices, these methods would eliminate bargaining among

\footnotetext{
${ }^{24}$ Auctions are sometimes used to address this and related issues, but introducing a currency for bidding raises a host of new problems that we will not try to analyze here.
} 
parties - and the costs associated with such bargaining — but bargaining within parties about which ministries to choose, and who gets what ministry, would continue.

If party leaders are more satisfied by a method that is considered fair, the government coalition is likely to be more stable. Satisfaction can further be enhanced, we believe, by using the two-party bargaining mechanism that induces sincere choices and balanced alternation — when each is appropriate — and by allowing trades of ministries among parties after their selection. Thereby some of the problems of cabinet selection can be ameliorated if not solved.

\section{Appendix}

To formalize the two-party mechanism discussed in section 6 for implementing sincere outcomes, which are Pareto-optimal (Brams and Straffin, 1979), assume the selection of items proceeds according to the following rules:

1. Two parties, A and B, alternate choosing single items from some set.

2. After the first party to select an item has made its choice, either party can make an offer to swap the item it chooses for an item already chosen by the other party.

3. This offer is placed on hold until all items have been chosen.

4. Starting with the most recent offer and going back to the first offer made by a party, each party accepts of rejects the offer it receives.

5. If a party accepts an offer, a swap is made; otherwise, there is no swap.

Proposition. If either A or B makes an insincere choice by "skipping over" one or more sincere choices (see section 6), the other party can induce an outcome for itself at least as good as the sincere outcome and sometimes a better one. 
Proof. Let A be the party at any point in play that makes an insincere choice from among the items still available. Let $x$ be the item that B ranks highest among the one or more items that A skipped over to make its insincere choice.

Now consider B's highest-ranked item, $y$, among those items still available. If the preferences of A and B are strict (i.e., there are no ties), there are two possibilities:

(i) B ranks $y$ higher than $x$, or $y>_{\mathrm{B}} x$. Because B prefers an item among those still available $(y)$ to the highest-ranked item that A skipped over $(x)$, B has no reason to offer to swap $y$ for $x$.

(ii) $x>_{\mathrm{B}} y$. Because B prefers an item that A skipped over $(x)$ to its highest-ranked item among those still available $(y)$, B has reason to offer to swap $x$ for A's $y$.

If B makes an offer in case (ii), A will find it rational to accept this offer, because A prefers $y$ to $x$, or $y>_{\mathrm{A}} x$, since A skipped over its preferred item $y$ to choose $x$. Hence, $\mathrm{A}$ as well as B will benefit when this swap is made. Moreover, in this case the sincere outcome will always be restored if only one item is skipped over in all instances of case (ii).

If A skips over more than one item, it may not be optimal for B to offer a swap even though a rational swap is possible. ${ }^{25}$ In this situation, we assume that B will not offer A a swap if not offering leads to a better outcome for B than the sincere outcome it can induce with a rational swap (as illustrated by the example in note 22).

\footnotetext{
${ }^{25}$ For example, assume A ranks four items 1234 and begins by choosing item 3. Assume B's preferences are 1324 . Then B should choose item 1 next — and not offer B a swap, even though there is a rational swap of item 2 for item 3 that B could offer A-whence A will rationally choose item 2 and B item 4, giving 23 to A and 14 to B. Clearly, 14 is better for B than its sincere allocation, 34, so not all offers to swap need be rational if a player skips over more than one item.
} 
B may also do better than its sincere outcome, and A worse, if A skips over an item that B does not prefer to an item still available. For then A may not be able to obtain the preferred item that it skipped over if B (rationally) chooses this item next. ${ }^{26}$ In sum, B can guarantee for itself an outcome at least as good as the sincere outcome, and sometimes a better one, if A skips over one or more preferred items. Q.E.D.

\footnotetext{
${ }^{26}$ For example, assume A ranks four items 1234 and begins by insincerely choosing item 2. Assume B's preferences are 2341 . Then B should choose item 1 and offer to swap it for A's item 2. So far so good. But now assume that A next (foolishly) chooses item 4, skipping over its preferred item 3. Then B should sincerely choose item 3, giving A allocation 14-after the rational swap of items 1 and 3-and B allocation 23. Thereby B does better than its sincere allocation of 13 , and A does worse than its sincere allocation of 24.
} 


\section{References}

Balinski, Michel L., and H. Peyton Young (2001). Fair Representation: Meeting the Ideal of One Man, One Vote, $2^{\text {nd }}$ ed. Washington, DC: Brookings Institution Press.

Blais, André, and Louis Massicotte (2002). “Electoral Systems.” In Lawrence LeDuc, Richard S. Niemi, and Pippa Norris (eds.), Comparing Democracies 2: New Challenges in the Study of Elections and Voting. London: Sage, pp. 40-69.

Blondel, Jean, and Maurizio Cotta (eds.) (1996). Party and Government: An Inquiry into the Relationship between Governments and Supporting Parties in Liberal Democracies. Houndmills, UK: Macmillan Press.

Brams, Steven J, Paul H. Edelman, and Peter C. Fishburn (2002). "Fair Division of Indivisible Goods.” Preprint, Department of Politics, New York University.

Brams, Steven J., Paul H. Edelman, and Peter C. Fishburn (2001). "Paradoxes of Fair Division.” Journal of Philosophy 98, no. 6 (June): 300-314.

Brams, Steven J. Brams, and Peter C. Fishburn (2000). "Fair Division of Indivisible Items between Two People with Identical Preferences: Envy-Freeness, ParetoOptimality, and Equity." Social Choice and Welfare 17, no. 2 (February): 247267.

Brams, Steven J., and Daniel L. King (2002). "Efficient Fair Division: Help the Worst Off of Avoid Envy?” Preprint, Department of Politics, New York University.

Brams, Steven J., and Philip D. Straffin, Jr. (1982). "The Apportionment Problem” (review of Balinski and Young, Fair Representation, Yale University Press, 1982). Science 217, no. 4558 (30 July): 437-438. 
Brams, Steven J., and Philip D. Straffin, Jr. (1979). “Prisoners' Dilemma and Professional Sports Drafts.” American Mathematical Monthly 86, no. 2 (February): 80-88.

Browne, Eric C., and John Dreismanis (eds.). Government Coalitions in Western Democracies. New York: Longman.

Budge, Ian, and Hans Pieter Keman (1990). Parties and Democracy: Coalition Formation and Government Functioning in Twenty States. Oxford, UK: Oxford University Press.

Carmignani, Fabrizio (2001). "Cabinet Formation in Coalition Systems.” Scottish Journal of Political Economy 48, no. 3 (August): 313-329.

Colomer, Josep M. (2001). Political Institutions: Democracy and Social Choice. Oxford, UK: Oxford University Press.

Cox, Gary W. (1997). Making Votes Count: Strategic Coordination in the World's Electoral Systems. Cambridge, UK: Cambridge University Press.

Edelman, Paul H., and Peter C. Fishburn (2001). "Fair Division of Indivisible Items among People with Similar Preferences.” Mathematical Social Sciences 41, no. 3 (May): 327-347.

Grofman, Bernard, and Peter van Roozendal (1997). "Modeling Cabinet Durability/Cabinet Termination: A Synthetic Literature Review and Critique." British Journal of Political Science 27, no. 4 (October): 419-451.

Herreiner, Dorothea, and Clemens Puppe (2002). "A Simple Procedure for Finding Equitable Allocations of Indivisible Goods.” Social Choice and Welfare 19, no. 2 (February): 415-430. 
Kohler, David A., and R. Chandrasekaran (1970). "A Class of Sequential Games.” Operations Research 19, no. 2 (March-April): 270-277.

Laver, Michael, and W. Ben Hunt (1992). Policy and Party Competition. New York: Routledge.

Laver, Michael, and Norman Schofield (1998). Multiparty Government: The Politics of Coalition in Europe (reprint, with a new preface). Ann Arbor, MI: University of Michigan Press.

Laver, Michael, and Kenneth A. Shepsle (1996). Making and Breaking Governments: Cabinets and Legislatures in Parliamentary Democracies. Cambridge, UK: Cambridge University Press.

Laver, Michael, and Kenneth A. Shepsle (eds.) (1994). Cabinet Ministers and Parliamentary Government. Cambridge, UK: Cambridge University Press.

Marshall, Albert W., Ingram Olkin, and Friedrich Pukelsheim (2002). “A Majorization Comparison of Apportionment Methods in Proportional Representation.” Preprint, Department of Mathematics, University of Augsburg, Augsburg, Germany.

Müller, Wolfgang C., and Kaare Strøm (eds.) (2001). Coalition Government in Western Europe. Oxford, UK: Oxford University Press.

O’Leary, Brendan, Bernard Grofman, and Jorgen Elklit (2001). "The Use of Divisor Mechanisms to Allocate and Sequence Ministerial Portfolio Allocations: Theory and Evidence from Northern Ireland.” Preprint, Department of Political Science, University of Pennsylvania.

Rae, Douglas W., and Michael Taylor (1970). The Analysis of Political Cleavages. New Haven, CT: Yale University Press. 
Strøm, Kaare (1990). Minority Government and Majority Rule. Cambridge, UK: Cambridge University Press.

Taagepera, Rein, and Shugart, Matthew Soberg (1989). Seats and Votes: The Effects and Determinants of Electoral Systems. New Haven, CT: Yale University Press.

Van Deemen, Ad. M.A. (1997). Coalition Formation and Social Choice. Boston: Kluwer Academic Publishers.

Warwick, Paul V. (2001). "Coalition Policy in Parliamentary Democracies: Who Gets How Much and Why." Comparative Political Studies 34, no. 10 (December): $1212-1236$.

Warwick, Paul V. (1994). Government Survival in Parliament Democracies. Cambridge, UK: Cambridge University Press.

Warwick, Paul V., and James N. Druckman (2001). "Portfolio Salience and the Proportionality of Payoffs in Coalition Governments.” British Journal of Political Science 31, no. 4 (October): 627-649.

Young, H. Peyton (1994). Equity in Theory and Practice. Princeton, NJ: Princeton University Press.

Young, H. Peyton (1995). "Dividing the Indivisible.” American Behavioral Scientist 38, no. 6 (May): 904-920. 